\title{
Os limites do lugar no ocidente: breve revisão das circunscrições topológicas
}

\author{
Wellington Amâncio da Silva ${ }^{a}$ \\ a Grupo de Pesquisa em Ecologia Humana, Universidade Estadual da Bahia, Paulo Afonso, 48608-240, Brasil. \\ welliamancio@hotmail.com
}

Recebido: 8 dezembro 2016 / Aceito: 11 janeiro 2017 / Publicado online: 15 fevereiro 2017

\begin{abstract}
Resumo
Nessa revisão é discutido como as representações topológicas - aquelas que dizem o que são os lugares e espaços - são utilizadas para fins políticos, econômicos e ecológicos, a partir dos seus discursos de verdade e legitimidade de conceitos de mundo. Foram analisadas as circunscrições do lugar no Ocidente, considerando os indivíduos e suas localizações, em formas de agregar e segregar. As representações aqui consideradas se caracterizaram por meio de figuras circulares em linhas intransitivas e sedimentadas a partir de hierarquias e estamentos. Tais divisões apontam para o que convencionou-se denominar, na modernidade, de grupos sociais, linhagens, castas, etc. Além dos aspectos circunscritivo, desagregativo e excludente do outro, há um forte caráter de afastamento negativo do meio ambiente em relação ao lugar constituído idealista e politicamente: a cidade, os espaços urbanos ideais. Há um forte caráter de afastamento negativo do meio ambiente em relação ao lugar devido a formação das cidades, consideradas como os espaços urbanos ideais.
\end{abstract}

Palavras-chave: Ambiente, ecologia humana, ecossistema, espaço urbano.

\section{Limits of the place in the West: notes about the topological circumscriptions}

\begin{abstract}
In this review is discussed how the topological representations - those that say that they are the places and spaces - are used for political, economic and ecological ends, from their speeches of truth and legitimacy of world concepts. It were analyzed as circumscriptions of the place in the West, considering the individuals and their locations, in ways of aggregating and segregating. The representations here, they are characterized by circular figures in intransitive lines and sedimented from hierarchies and estates. Such divisions point to what has been conventionally termed, in modernity, social groups, lineages, castes, etc. In addition to two circumscribing, disaggregating and excluding of the other, there is a strong negative environmental character in relation to the constituted place Idealist and politically: the city, the ideal urban spaces. There is a strong negative character of the environment in relation to the place due to the formation of the cities, considered as the ideal urban spaces.
\end{abstract}

Keywords: Environment, human ecology, ecosystem, urban space.

\section{Introdução}

De uma perspectiva subjetiva, o lugar sempre ocupou nossos pensamentos, discursos e representações; sempre nos intrigou, despertando nosso interesse e suscitando questionamentos, muitas vezes balizados por significações já estabelecidas no arcabouço de cada cultura que assim o pensou.

Tivemos até o momento a oportunidade de protagonizar os sentidos desse fenômeno, e, a partir da sua constituição conceitual, vivenciá-lo. Sabemos, pois, que noutras vezes, ao concebermos o lugar, como tópos e como conceito, assim o fizemos numa perspectiva ora de distanciamento de outros ecossistemas, ora de aproximação, identificação, correlação, interdependência - e tal proximidade é maior quanto mais próxima for a comunidade do meio ambiente em significação, vivência e localização reconhecida; antes, predominou na maioria das vezes, pensarmos o lugar de modo binário: deste lado, temos uma perspectiva de cultura humana, por assim dizer, equidiferente, equidistante, como o oposto da natureza intocada, segundo Diegues (2001), por exemplo demonstrou.

Mas, em vista disso, consideramos a emergência de paradigmas e epistemologias que corroboram para pensar e viver o lugar em meio a outras dimensões ecológicas, como um fenômeno intrínseco do meio ambiente e de integração da diversidade ecoexistencial.

A ecoexistencia postulado de que a variedade de vidas, não apenas a humana, também se faz participante de direitos existenciais, visto que cada ser já cumpre seu dever, isto é, sua função biológica precisa dentro de um ecossistema. A partir deste conceito podemos ampliar e aprofundar os sentidos de direitos e deveres fazendo justiça em vista de transcendê-los do âmbito social para o ecossocial.

Devemos considerar o interesse pelo tema lugar a partir de seus sentidos, isto é, como uma instância condicionada às 
possibilidades e condições ser (Heidegger, 2006), sem desconsiderar as existências dos demais seres viventes nesta ontologia. Sabemos, pois, que o modo como pensamos o lugar e o que este significa para nós repercute diretamente na forma como interagimos com o meio e com o outro - e está é uma importante questão ecopolítica, visto que a exploração dos espaços do meio ambiente está condicionada à exploração de outros seres humanos nestes espaços.

Nessa revisão é discutido como as representações topológicas - aquelas que dizem o que são os lugares e espaços - são utilizadas para fins políticos, econômicos e ecológicos, a partir dos seus discursos de verdade $\mathrm{e}$ legitimidade de conceitos de mundo.

\section{As circunscritividade topológicas no Ocidente}

Antes é preciso considerar algumas representações e sentidos do lugar na história; para sabê-lo, tratamo-lo aqui a partir do discurso circunscritivo presente na cosmologia europeia. Por exemplo, Casey (1997) afirmou que o interesse pelo tema lugar era uma constante desde os pré-socráticos até cerca de 1600 da Era Comum. Por exemplo, antes das elaborações geográficas e ecológicas atuais - sobre o lugar, a paisagem ou o espaço extensivo - o tópos onde nos encontrávamos localizado chamava-se $\Gamma \alpha \tilde{\imath} \alpha$ (Gaea, gaîa) ou $\gamma \tilde{\eta}(g \hat{e})$, palavras gregas utilizadas para denominar a Terra; também de onde se deriva a expressão yévos (genos) vida e origem, de cujos derivam-se as palavras gênesis, genética, gene, geração. Portanto, Gaea ao mesmo tempo em que foi compreendida como a habitação universal dos seres viventes e não viventes, também era a fonte de toda vida. Xenófanes (570 a.C.-475 a.C) compreendia Gaea como "uma divindade que ensina a justiça a todos aqueles que podem aprender".

Platão, por exemplo, concebia Gaea como "um alguém visível que continha em si todas as criaturas vivas" (Sale, 2000 , p. 3). Nesse enlace de pertencimento e fonte de autoidentificação do ser, Platão definiu-a posteriormente como alimento do ser - não apenas no sentido de provisão das nossas necessidades fisiológicas, mas das nossas necessidades existências, identitários, de pertencimento, de autossignificação.

Cada vez que os seres humanos compreendiam suas possibilidades de existência como uma interação conquistada por eles mesmos, e as condições dessa existência ofertadas em aquiescência de Gaea, mais esta estabelecia-se para eles como um lugar de convivência; adaptar-se é antes de tudo constituir um lugar e a resiliência é exitosa num tópos em cujos sentidos transitam afetividade, desejo, memória e estima ao lugar, ao meio ambiente em geral (Schama, 1996).

Mais tarde, quando o habitar é institucionalizado, tornando-se pólis, um lugar de habitar entre iguais, no sentido da sua natureza política, Platão (428-348 E.C.), um cidadão aristocrata grego, sente-se inspirado para explicar o кó $\sigma \mu \varsigma$, o mundo ordenado, através da redação de um dos seus últimos diálogos, Timeu - é preciso clarificar os sentidos de cosmo no âmbito desta igualdade platônica: não eram iguais, o estrangeiro, a criança, a mulher e o escravo. O idoso era ainda um igual, porque algo do valor da tradição oral era valorizado naquele momento, porém em fase crepuscular; com a ascensão do livro, o qual Platão havia criticado, a tradição oral cairia em desuso em todo o Ocidente civilizado. A transição, do Mito para a Filosofia, de Homero para Sócrates, da "Odisseia" para "A República de Platão", marca o fím do longo ciclo dessa forma característica de saber - a nova visão de mundo traz consigo novas formas de vivenciá-lo.

Em Timeu, o mundo foi gerado por um Demiurgo, a partir do que tinha disponível naquele momento: a ataxia, a desordem originária, ou o conglomerado de matérias preexistentes, fonte primordial de tudo; a partir das ideias e da formas como modelos, o Demiurgo trabalha sobre a ataxia, constituindo para nós o mundo conhecido. Com efeito, ideia e forma seriam, por assim dizer, categorias subjetivas do próprio Demiurgo, e, por conseguinte, da subjetividade explicativa do autor de Timeu.

Assim, de uma perscrutação de mundo a partir do lócus ideal da pólis, teríamos um discurso hegemônico - de abstração e concretude, de espírito e matéria, de essências nobres e entes como representações pequenas destas essências -, que perdurou toda a Antiguidade Ocidental; dele se prefiguraram as representações do mundo, do espaço, do lugar, da própria concepção de natureza e, por extensão, do meio ambiente (que também é apenas um conceito cuja finalidade devemos compreender) - essas representações eram o que tínhamos de melhor como referenciais de interação.

A partir da leitura de Cresswell (2013), temos outra expressão antiga, muito significativa: Chora palavra que era um terno tratado por Platão como processo de se tornar, isto é, o caminho em que a existência toma forma a partir do vazio, do Kenon. Tornar-se é, pois, em Platão, um processo que envolve três fatores: a) o que tornar-se, b) aquilo que é o modelo para se tornar, c) o lugar como "ponto ajustador" para se tornar (Casey, 1997).

Este último elemento da chora é um termo que implica tanto extensão no espaço bem como o ser, a coisa, o acontecimento naquele espaço que está em processo de se tornar. Portanto, o lugar é a plataforma ontológica onde os sentidos são constituídos para nós - o próprio Aristóteles reconhecia que a força do lugar era extraordinária.

A ecologia humana daquele período partia do princípio de ordenação do espaço. Hoje reconhecemos o espaço como uma das cinco dimensões conceptuais da sustentabilidade. Mira (2014), denuncia o seu desenvolvimento em prejuízo das outras dimensões. São todas elas: a social, a econômica, a ecológica, a espacial e a cultural. Espaço como possibilidade de ser lugarizado, isto é, de passar a ser alguma coisa desejada por meio do processo de constituir-se no meio ambiente um lugar de habitar para si e para os seus, através de concretizações geográficas subjetivas, a saber, a cidade, o vilarejo, o condado, a rua, a casa - e ainda as suas abstrações, tais como a ideia de lugar, a memória do lugar e o projeto de lugar -, tendo, a partir da representação circular uma ordenação hierárquica centro/periférica, onde estava centralizado o castelo, num primeiro plano; as casas dos nobres, em segundo plano; as casas dos trabalhadores manufatureiros, em terceiro plano; em seguida, as casas dos servos entremeadas ao espaço agrícola e pecuário, a se perder na extensão das florestas e vales como localização imprecisa e afastada à periferia de significação e similitude a um tópos reconhecidamente estabelecido nos planos acima citados. Por fim, o espaço florestal, desconhecido - disso, o periférico seria sempre o 
incógnito, e para além dele, talvez o nada.

De todo modo, o lugar era o resultado e a forma da adaptabilidade própria de uma comunidade, em vista das tecnologias, materiais, e ideias disponíveis, que propiciavam a constituição de um tópos para a manutenção da vida; nessa localidade política, gregária, de convivência consigo, com o outro e com o meio ambiente, o lugar se configurava como propriedade, fronteira de direito inalienável, limítrofe do meu e do nosso intransponível para o outro, assim, o oĩkos, a casa, o lar de todos, tinha seus limites para as questões do nosso, do meu, do seu, do outro.

Pensamos que na Antiguidade, o mundo ordenado, $\kappa o ́ \sigma \mu o \varsigma$, era visto a partir de uma perspectiva de habitação, ou de possibilidade de habitar - o lugar era a materialização do que antes era subjetivo ou impreciso, contingente; o lugar tornava-se para nós a representação da ordem, da norma, do arranjo, da continuidade, da adaptação humana localizada num percurso do meio ambiente; na maioria dos textos gregos, a palavra $\kappa o ́ \sigma \mu o \varsigma$ além de significar ordem também possuía o sentido de arranjo; essa última expressão é muito significativa quando relacionando ao conceito de lugar.

A melhor forma, por assim dizer, de representar a ordem era como circunscrição, delimite, fronteira - por assim dizer, suas instâncias políticas (Figura 1); a melhor forma, por assim dizer, de representar a ordem era como circunscrição, delimite, fronteira, e, por consequência, a estamentação do lugar, do meio ambiente e dos grupos sociais. Segundo Virilio (1993, p. 9), “[...] desde o cercado original, a noção de limite sofreu mutações que dizem respeito tanto à fachada quanto ao aspecto de confrontação". Nesses dois aspectos, cercar e delimitar são representações de poder que se sustentam em um discurso que se justifica pelo afastamento violento do outro do lugar que é meu- dessa circunscritividade, isto é, da capacidade de manter fronteiras, surge a confrontação entre as vizinhanças inóspitas justamente devido às representações de separação/circunscrição. Acerca do que suscita o confronte, Nietzsche $(2005$, p. 131, 4) dizia: "Conduzis uma guerra? Temeis os vizinhos? Retirais as pedras fronteiriças e não tereis mais vizinhos".

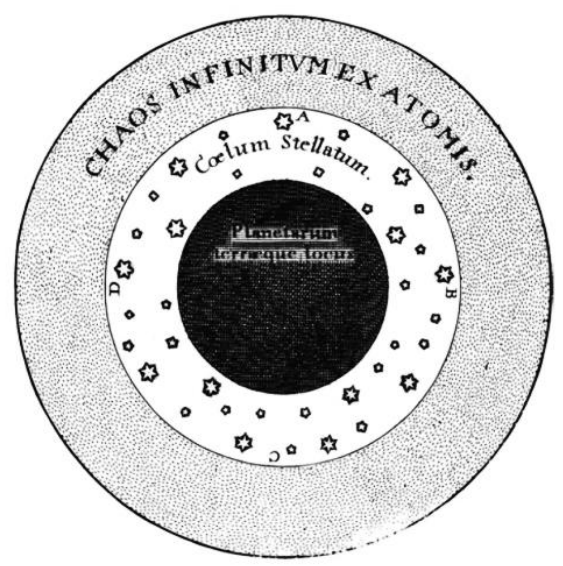

Figura 1. Universo atomista de Demócrito (Heninger, 2004).

No Universo atomista de Demócrito (Figura 1), temos a representação de um mundo fechado (Koiré, 2010); percebe- se a profunda ideia de circunscrição como mecanismo representacional topológico cujas pretensões de ordenar e normatizar o espaço da natureza contingencial são postas em hierarquias, distribuídas a partir do centro conhecido à periferia desconhecida. A área central escura é composta pela Terra e pelos planetas, cercados por uma esfera estelar de espessura similar a densidade da terra e dos planetas, como espaços precisos, portanto, similar: Demócrito propunha a explicação dos modelos celestes pelos modelos terrestres como unificação, ordenação e inteligibilidade do universo (Koiré, 2010). Fora das estrelas jaz o chaos infinitum ex atomis, o caos infinito de átomos, a ataxia, que se desloca de forma aleatória, ininteligível: fora do centro jaz a incógnita no caos extensivo.

Assim, no intuito de representar o lugar, de torná-lo compreensível, de conferir um nome, seria devido circunscrevê-lo, "ordená-lo" como figura estática. Dito isso, mesmo o espaço infinito, desconhecido e caótico, no intuito de ser compreendido, deveria ser representado como espaço circunscrito e, por consequência, reduzido. E é o círculo, a linha que se fecha, o limítrofe perfeito, que irá convencer e configurar os sentidos do lugar como uma representação universal de fronteira política - noção que perdurará até os tempos atuais.

Por outro lado, supomos que na Antiguidade a representação do chaos infinitum ex atomis fosse comumente relacionada, numa escala menor, às heterotopias inerentes ao meio ambiente, isto é, aos espaços para além da cidade, tais como a floresta, as matas, os bosques, os mares, as montanhas, bem como os espaços íngremes, de difícil adaptação ou que por algum motivo não despertassem interesse - espaços, por vezes, improdutivos e de banimento.

Outro exemplo pertinente sobre a representação do mundo foi descrito por Kragh (2007) a partir do Coelum empireum habitaculum dei et ominium electorum de Petrus Apianus (Figura 2). Segundo Kragh (2007, p. 40), “encontramos um tipo diferente de cosmologia em algumas das obras-primas literárias do mundo medieval", por exemplo, temos uma

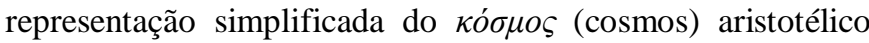
que consiste em sete esferas planetárias como nosso Sistema Solar conhecido no período; temos ainda a representação do universo visível por meio de uma imensa esfera de estrelas fixas (o Stellatum) e a partir daí um espaço vazio, sem qualquer estrela [Nonv Coelum], tal representação está de acordo com o pensamento de Aristóteles, que afirmava que fora do mundo visível não há corpo, nem lugar ou mesmo espaço vazio, nada existe fora do mundo.

Ainda na Figura 2, após a representação do vazio, está situado o chamado Decimum Celum [Décimo Céu], o lugar do primum mobile [Motor Primeiro], o local da divindade, do Demiurgo. Observe que o décimo céu, o céu de deus possui um limite acima dele. Seria o lugar da Ataxia de Timeu de Platão? Esse fato demonstra como na Antiguidade e depois, ao seu modo na Idade Média, havia a necessidade de circunscrição como ordenação representacional do mundo.

Pergunta-se de que forma esse conjunto de representações topológico repercutia no cotidiano das pessoas servindo-lhes de referencial de mundo enquanto recursos disponíveis de entendimento e interação. 


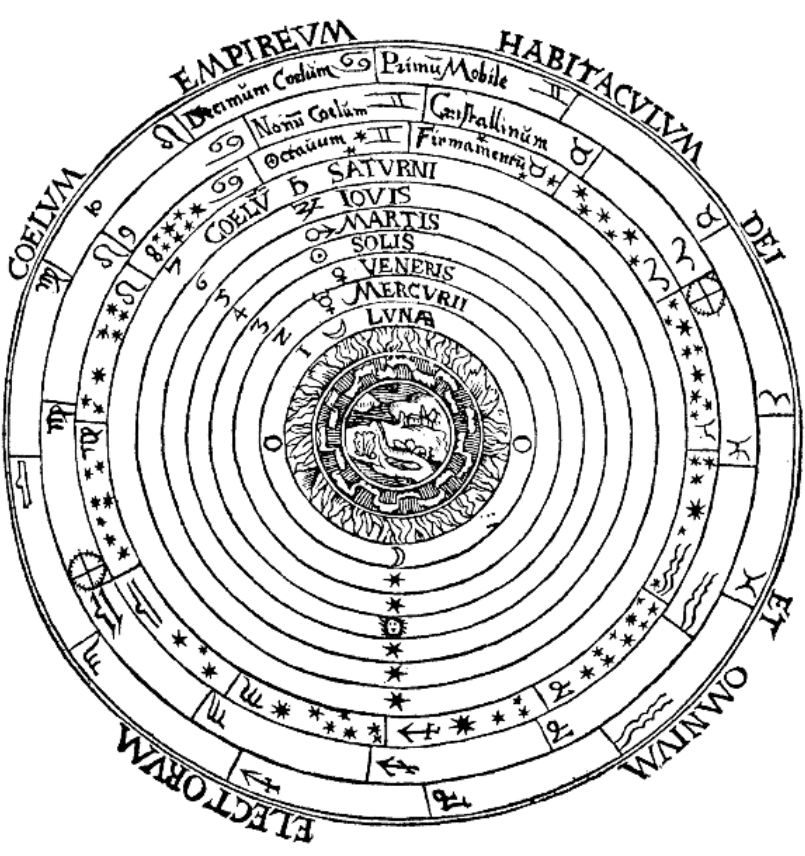

Figura 2. Império celeste e morada de Deus e de todos os eleitos segundo Petrus Apianus, em1533 (Kragh, 2007).

Como as circunscrições constituíram as representações e os discursos sobre o lugar no Ocidente? Podemos refletir isso a partir da afirmação de que delimitação e confrontação constituem a gênese dialética nas "lugarizações" do humano.

Um bom exemplo é o de Estrabão, geógrafo, historiador e filósofo grego, demonstrou que o reconhecimento da geografia era indispensável para o governo adequado e para a arte de governar - Além de sua vasta importância no que diz respeito à vida social, e a arte de governar, a Geografia desdobra-nos a fenômenos celestes, nos familiarizando com os ocupantes da terra, dos oceanos, da vegetação, das frutas e peculiaridades dos várias partes da terra, o conhecimento de que marca aquele que cultiva-o como um homem sério diante dos grande problema da vida e da felicidade.

Assim, é pertinente destacar o aspecto subjetivo político dessas representações: a ordenação do céu em hierarquias elevadas de poder, tópos de inalcançável habitação, de limítrofe, de proibição para os não iniciados, para os infiéis, fechado à comunidade em geral, lugar apenas para ominium electorum, "para todos os eleitos", poderá ter exercido influência sobre os sentidos e significados dos lugares da cidade e do campo (Williams, 1990), por meio de circunscrição em hierarquias políticas acessíveis e inacessíveis para alguns segundo certos status.

A historiografia pôde clarificar para nós as "formas de eleição" dos sujeitos nas diversas instâncias, instituições e lugares, dentro e fora da cidade, evidenciou para nós as formas de legitimação de posse, de instituição propriedade, de exploração o meio ambiente e as comunidades nativas. As cidades são hoje entendidas como ecossistemas onde ocorre toda essa dinâmica. É preciso reconhecer que a exclusão urbana não é diferente da exclusão rural. A cidade enquanto ecossistema urbano traz um outra racionalidade. No pensamento atual demonstra-se haver um continuum ruralurbano que alterou essa dicotomia que priorizava o lugar da cidade como ideal e determinante em relação aos demais espaços habitados ou não.

Essas representações foram ao mesmo tempo constituindo tipos de lugares bem como permeando os lugares anteriormente disponíveis, dando livre passagem para uns, dispersando e proibindo a presença de outros em certos espaços, bem como interditando os indesejáveis e banindo a muitos.

Segundo Foucault (2013), lugar na Idade Média era concebido a partir de hierarquias, geralmente em duas dimensões contrapostas: lugar do sagrado ou do profano; lugar protegido, defendido, fechado ou do seu inverso; lugar do urbano ou lugar do rural; os topoi imagéticos do celeste ou o umbraticus localis; de uma perspectiva cristã, negativa em relação à cidade, que talvez sintetize o mito do banimento do homem da natureza, Kotkin cita o teólogo Jaques Ellul, lembrando-nos de que a cidade está ligada à queda humana do espaço da graça e representa a tentativa de criação de uma nova ordem. Fomos expulsos do Éden. E Caim construiu uma cidade para substituir o jardim divino [...]. Seu fundador foi o primeiro assassino [humano] de que se tem notícia (RISÉRIO, 2013).

Temos ainda o lugar do privado em contraposição ao público. Acerca disto, Arendt (2007) faz uma discussão interessante sobre Esfera Privada (o Comum) e Esfera Pública (A Propriedade), o que corresponde também ao que se costuma descrever por espaço privado em oposição ao espaço público.

Existiam os lugares de deslocamento, de e para transições, lugares de repouso ou de afastamento. Em oposição ao lugar de habitar, de estadia, o banimento visava dispersar o ser humano em espaços desconhecidos. Portanto, se os espaços medievais corresponderiam a um desejo de localização, um desejo complexo de habitar, fazendo um lugar nesses espaços; isso correspondia a um processo de racionalização do espaço inaudito em lugar identificado como adaptabilidade. Assim, na Idade Média é bem visível uma economia do espaço, ao qual Foucault (2013) denomina de espaço de localização.

No século XVII Galileu revoluciona a percepção do lugar, ao fazer sua dessacralização teórica do espaço, isto é, ao devolver a Terra seu percurso originário ao redor do Sol - o que se postulou chamar de conceito heliocêntrico. Com essa teoria temos um espaço agora em aberto, infinito que abala nossas concepções de habitar, tanto porque o lugar como tópos diminui imensamente, bem como este, enquanto localização precisa, tem condicionados seus significados no devir do espaço a ser explorado e colonizado; o lugar, em face do universo, é uma imprecisão, um ponto indeciso num espaço em movimento, e assim, há um afastamento momentâneo do dito de Platão, do lugar de habitar (Gaia) como "alimento do ser" e a crescente a pergunta sobre o que somos.

A partir do século XVII, "a extensão toma lugar da localização" (Foucault, 2013, p. 415), a extensão, pois, suscita a possibilidade de alcances (abstrato, conceitual, projetivo, mapeante, escalar, matemático) de terras distantes - e temos assim uma mudança paradigmática de um mundo fechado da Antiguidade ao universo infinito da Idade Média até a Modernidade (Koiré, 2010. p 99).

Dessas representações do espaço infinito surgiriam imprecisões topográficas e a emergência de diversas heterotopias dentro e fora do lugar, dentro e fora do meio 
ambiente, visto que o espaço não é homogêneo, existem rupturas e porções do espaço qualitativamente diferentes. Aqui é importante ressaltar que enquanto "a geometria opera sobre um espaço abstrato, vazio de todo o conteúdo, disponível para todas as combinações. Holzer (2014, p. 1) esclarece sucintamente que "espaço é um termo genérico e abstrato, ligado à geometria euclidiana e à física newtoniana". O espaço geográfico tem um horizonte, um modelo, cor, densidade. Ele é sólido, líquido ou aéreo, largo ou estreito: ele limita e resiste" (Dardel, 2011, p. 2).

De todo modo, o interesse se volta para a Terra, tendo com proeminência uma abordagem política e econômica do espaço como extensão a ser conhecida, definida e representada, a partir da "mudança da nossa imagem do universo e do lugar que ocupamos nele." (Berman, 1996, p. 9).

Segundo Cresswell (2013), o conceito de Kenon, por exemplo, refere-se ao vazio, "espaço" em que existem todas as outras coisas - um reino homogêneo e indiferenciado. Kenonis, por exemplo, representa a abstração de alguma coisa do seu entorno; é extensão pura. Esta noção de vazio eterno, de ponto zero limítrofe a partir de onde se iniciam as investigações sobre o espaço - e consequentemente dos seus significados para nós - se tornou a base científica e abstrata, dessas noções de espaço - e aqui, vale destacar que o espaço não conhecido ou indiferenciado contém conceitualmente algo do vazio (consequentemente urge ser preenchido, povoado, racionalizado). Essas noções de espaço foram desenvolvidas por Descartes e Newton, entre outros, e constitui a base para todos os tipos de ciência que dependem de noções abstratas de espaço.

A partir desses filósofos, como uma necessidade de conhecer e assim, preenche o vazio de sentidos, emergem novos conceitos geográficos de espaço. (A partir daí, espaço foi concebido como um conceito orientador para empreendimentos geográficos a partir da descrição e do mapeamento com o intuito de conquistas territoriais, no sentido de exploração e colonização, implantação de novos mercados); espaço como dimensão mensurável, do tópos em detrimento da reflexão sobre lugar, (dimensão subjetiva e existencial no tópos). Destarte, é preciso desconstruir o discurso dessa Geografia oficial em sua finalidade descritiva, distanciada, analítica e pouco vivencial, visto que:

A expressão geografia, utilizada no sentido de descrição da Terra, é infeliz e tem confundido as pessoas; parece-nos que com isso simplesmente refere-se aos elementos, cujos fatores são a verdadeira ciência da geografia. Esta ciência tenta possuir a mais completa e cósmica imagem da Terra; resumir e organizar em uma bela unidade de tudo o que conhecemos do globo [...]. A geografia é a parte da ciência que estuda o planeta em todas suas características, fenômenos e relações, como uma unidade interdependente [...] (Ritter apud Capel, 2004).

Dito isso, os estudos do espaço, por meio dessa Geografia narrativa e "mapeativa", serviam mais a interesses políticos e econômicos específicos daquele período, tais como os de expansão, colonização e exploração territorial (Relph, 2012, 19); Segundo Berdoulay e Entrikin (2012), o conceito de território em Geografia, não facilitaria a compreensão das múltiplas territorialidades presentes na contemporaneidade como caracterizações da vida social e da cultura.

Enquanto durou o colonialismo do século XX manteve-se hegemônica e para tais fins, essa epistemologia geográfica onde seu paradigma de espaço mensurável foi uma ferramenta apriorística e possibilista de colonização - porque a exata mensuração era pré-requisito para um alcance colonialista, gerido, preciso e efetivo de espaços distantes.

Por outro lado, os aspectos subjetivos e humanos dos espaços habitados, dos lugares, eram assunto de uma nova ciência, a Antropologia nascida do início do século XVIII, deste modo, podemos por assim dizer que o interesse antropológico sobre os nativos tinha um forte caráter escravista, mesmo que apenas no sentido de dizê-los quem são.

Por conseguinte, os elementos dominantes do século XVII e XVIII - e aqui se incluir o espaço geográfico como visão de mundo científica - foram aceitos rapidamente e exaustivamente, porque eles se conformavam, de modo paradigmático, eficaz e harmoniosamente, às necessidades econômicas e políticas do período (Sale, 2000).

Acima de tudo, a profundidade da nova forma de conceber o mundo natural dessa ciência [...] foi abraçada ardentemente como a peça vital e central da cultura européia, o instrumento definidor do que fora todas as outras sociedades do passado, aquele que permitiu os seres humanos do passado tomar seu lugar "legítimo" no centro do palco terrestre. (Sale, 2000).

Temos aqui, a ciência positiva, como realização técnica, ideológica e econômica sobre o espaço colonizado - como se pode ver nos bons livros de história -, possuía "[...] uma combinação sinergética extraordinária e um sistema de ideias criativas e explicativas com uma construção política poderosa e processos econômicos de sucesso" (Sale, 2000).

Sob tal colonialismo político, econômico e geográfico, o lugar do humano nativo era insignificante, sem valor; em outras palavras, seus significados foram desconsiderados, sobretudo pela negação da alteridade nativa, por estar em desacordo com a visão de mundo da ratio na versão europeia.

Com efeito, a negação do lugar nativo enquanto cultura e humanidade distintas fora posteriormente resolvida pela aculturação em toda a sua dimensão unilateral, isto é, pela subsunção da cultura local no todo da cultura do colonizador em vista de encurtamento de distâncias, que no final das contas correspondiam à superação de entraves econômicos, no intuito de "criar uma comunidade de interesses, de crenças e de normas que contribuíssem para superar o obstáculo da distância" (Claval, 1984, p. 224).

Como resultado de cerca de trezentos anos de estudos do espaço físico, o conceito de Lugar, esteve presente muito mais na linguagem cotidiana do que como categoria especializada da terminologia acadêmica (Cresswell, 2008) e é na sua dimensão cotidiana que os sentidos de lugar ganham importância nos estudos atuais, sobretudo, a partir da Fenomenologia.

Para Relph (2012), a partir das fenomenologias de Husserl, Heidegger e Merleau-Ponty, evidenciamos que a ciência empírica deixa de fora os sentimentos, emoções, experiências e tudo que é humano. Ele ainda reitera que há mais de quarenta anos muito pouco havia sido publicado sobre o tema Lugar, em 
qualquer disciplina, tanto como conceito quanto como fenômeno da experiência vivida. Houve breves discussões sobre lugar como sentido - isto feito por diversos pesquisadores e estudiosos em suas respectivas áreas do saber - muito embora a produção dedicada a lugar estivesse ainda escassa, ao menos até o começo da década de noventa, o interesse da ecologia pelo lugar sempre esteve presente, apesar da separação disciplinar em blocos cartesianos e, portanto, de certo distanciamento entre outras áreas do saber.

Para Relph, lugar "tem sido interpretado a partir da perspectiva comportamental, humanista e fenomenológica" (1976, p.156). Conquanto, a tendência atual é a de revisão de textos dos diversos autores do passado recente; neste contexto, lugar tem sido afirmado diversas maneiras, a saber, como tópos de negociação comercial, de estratégia de vendas e de comércio cultural (Yúdice, 2004); da sua construção como cidade, condomínio, bairro planejados segundo determinados fins; tem-se visto o lugar como locus situado à ou por tribos urbanas - lugar em oposição a lugar como choque cultural (Silva et al., 2012).

Há uma perspectiva de estudos do lugar na condição de desabitar - uma espécie de paradoxo vivenciado hoje por povos atingidos por barragens e hidrelétricas; há discussões sobre o resgate cultural do lugar, a exemplo dos estudos em algumas comunidades quilombolas, motivadas pela Lei 20.417/2013 (Brasil, 2013) ao resgate da sua "cultura local" e das tradições mais remotas.

Em meio a todas essas perspectivas, há de sabermos os sentidos do lugar quilombola na contemporaneidade, quando em seus primórdios, quilombo fora lugar transição e/ou de refúgio; lugar de recomeço, resistência, de combate, de manutenção pluricultural de um modo de viver africano (brasileiro), lugar de interações humanas ambientais característico.

\section{A humanidade do lugar}

O lugar é sempre o tópos do humano, porém, não se resume a apenas isso; conforme Relph (2012), este se caracteriza como fenômeno das nossas experiências, no qual coexistimos e, por causa disso, também agrega ou dimensões subjetivas que nos suscitam uma amplitude de significados. Em seus aspectos de convivencialidade, o lugar não é apenas um ambiente próprio apenas do humano, mas em constantes intersecções com outros ecossistemas e com seus respectivos residentes.

Sendo assim, ao investigar os paralelos entre o conceito de lugar em Geografia Humanista e o conceito de meio ambiente em Ecologia Humana (BARROWS, 1923), reconhecendo o primeiro com ecossistema humano, ou ainda, o lugar como a dimensão humana da natureza habitada, no sentido de uma adaptação, sem por isso anular a diversidade ecossistêmica outrora inerente apena a natureza intocada (Diegues, 2001); a ecologia humana não dispensa a compreensão das interações com os elementos ambientais desta paisagem. E a compreensão desta paisagem não prescinde dos elementos biológicos e ecológicos intrínsecos ao ambiente. Se a paisagem é uma representação humana visual, Geografia Humanista e Ecologia Humana dialogam quando entram em consenso quanto à premência destes elementos ambientais nas interações percebidas de modo fenomênico. Assim, o lugar ao ser reconhecido no meio ambiente torna-se uma "instância" de ampla convivencialidade. Para Pires e Craveiro (2014, p.55), "a ecologia humana surge, assim, da necessidade de produzir conhecimento para compreender a relação do homem com o seu ambiente, para responder à interrogação de qual o seu lugar na Natureza". Esta perspectiva de lugar encontrar-se-á, antes na paisagem, o grau de relação humana, como intervenção arbitrária, sobre o ecossistema.

Nos primórdios do saber ocidental, Platão afirmava que o "lugar é o alimento do ser", sugerindo assim uma ontologia do lugar como a condição de sentidos do ser, onde o ser se reconstrói. Podemos aferir daí que é o lugar que fornece ao humano as possibilidades de sentidos para si (Malpas, 2004; 2006).

A perspectiva ontológica do lugar é anterior à perspectiva da Geografia, da História, da Economia, etc. Lugar é antes de tudo, uma importante categoria filosófica, visto que é impossível saber quem somos sem antes compreender onde estamos e o que fazemos da condição de estar. A ontologia do lugar é sempre ecológica, ecossistêmica por assim dizer, e, justamente com o humano implicado.

A perspectiva de lugar é sempre uma ecologia humana visto que somos apenas nós que a pensamos. Assim, lugar ecossistêmico busca entender e agrega a presença de uma ampla diversidade de vida em seu topos. Desta forma, sendo o lugar uma experiência humana numa plataforma ambiental, ao considerar o humano (húmus) como um ser implicado ao e constituído no meio ambiente, oferece um paradigma de reaproximação e não de distanciamento; de identificação e pertencimento, e não de estranhamento.

\section{Referências}

Arendt, H. 2007. A Condição Humana. 10. ed. Tradução Roberto Raposo. Rio de Janeiro: Forense Universitária. 407p.

Barrows, H. H. 1923. Geography as Human Ecology. In. Annals of Association of the American Geographers, 13(1), 1-14.

Berdoulay, V.; Nicholas, E. 2012. Lugar e Sujeito - Perspectivas teóricas. In: Marandola Jr., E.; Holzer, W.; Oliveira, L. (orgs.). Qual o espaço do lugar? São Paulo: Perspectiva, 2012. pp. 93-97.

Berman, M. 1986. Tudo que é sólido desmancha no ar - a aventura da modernidade. Tradução de Leonardo Lourenço. São Paulo: Companhia das Letras. 347p.

BRASIL. Decreto n. 20.417 de 11 de out. de 2013. Regularização fundiária de terras públicas estaduais, rurais e devolutas, ocupadas tradicionalmente por Comunidades Remanescentes de Quilombos e por Fundos de Pastos ou Fechos de Pastos. Assembleia Legislativa da Bahia. Disponível em: <http://www.redireito.org/wp-content/uploads/2016/12/lei-bahia.pdf>. Acesso em: 08 fev. 2017.

Capel, H. 2004. Filosofia e ciência na geografia contemporânea: uma introdução à geografia. Maringá: Massoni, 262p.

Castro, M. 2013. Sobre Paul Claval: impressões e registros geográficos. Goiânia: FUNAPE. 176p.

Casey, E. 1997. The fate of place: A philosophical history. Berkeley: University of California Press. 495p.

Cresswell, T. 2008. Place: An Introduction. Oxford: John Wiley \& Sons. 168p.

Cresswell, T. 2012. Geographic thought: a critical introduction. Oxford: John Wiley \& Sons. 298p.

Dardel, E. 2011. O homem e a terra: natureza da realidade geográfica. Tradução de Werter Holzer. São Paulo: Perspectiva. 160p.

Diegues, A.C.S. 2001. O mito moderno da natureza intocada. $3^{\mathrm{a}}$ ed. São Paulo: Editora HUCTEC. 169p.

Foucault, M. 2013. Heterotopias. In: Foucault, M. Ditos e Escritos III. Tradução de Inês Autran Dourado Barbosa. Rio de Janeiro: Forense Universitária, p. 114-124. 
Foucault, M. 2015. Utopias reais - ou lugares e outros lugares. Tradução de Carolina Dittrich. (n.t.) Revista Literária em Tradução. pp. 416-426.

Heidegger, M. 2006. Ser e tempo. Tradução revisada de Márcia Sá Cavalcante Schuback. Petrópolis, Bragança Paulista: Vozes, Universidade São Francisco. 598p.

Helge S. K. 2007. Conceptions of Cosmos - from myths to the accelerating universe: a history of cosmology. New York: Oxford University Press. $288 \mathrm{p}$.

Holzer, W. 2014. Sobre Territórios e Lugaridades. Revista Cidades, 10(17): 18-29.

Koiré, A. 2010. Do mundo fechado ao universo infinito. 4. ed. Tradução de Donaldson M. Garschagem. Rio de Janeiro: Forense Universitária. $304 p$.

Kragh, H. (2007). Conceptions of cosmos from myths to the accelerating universe: history os cosmology. Oxford: Oxford University Press.

Malpas, J.E. 2004. Place and Experience - A Philosophical Topography. United Kingdom: Cambridge University Press. p. 38. 228p.

Malpas, J.E. 2006. Heidegger's topology: being, place, world. USA: Massachusetts Institute of Technology. p. 55. 424p.

Mira, F. 2014. As cores da economia e o desenvolvimento sustentável. In: Marques, J. (org.). Ecologias Humanas. Feira de Santana-BA: UEFS. pp. 89-104. 460p.

Nietzsche, F. 2005. Genealogia da moral. Tradução: Paulo César de Souza. São Paulo: Companhia das Letras. p.131. 179p.

Pires, I.M., Craveiro J.L. 2011. Ética e prática da ecologia humana. Lisboa: Editora Apenas Livros. 30p.

Relph, E. 2012. Reflexões sobre a emergência, aspectos e essência de lugar. In: Marandola Jr. et al. Qual o espaço do lugar? São Paulo: Perspectiva, 2012.

Relph, E. 1976. Place and placelessness. London: Pion, 174p.

Risério, A. 2013. A Cidade no Brasil. São Paulo: Editora 34. 206p.

Sale, K. 2000. Dwellers in the land: The bioregional vision. Georgia: University of Georgia Press. 248p.

Schama, S. 1996. Paisagem e memória. Tradução de Hildegard Feist. São Paulo: Companhia das letras. 696p.

Silva, T.T.; Stuart, H.; Kathryn, W. 2012. Identidade e diferença. A perspectiva dos estudos culturais. Petrópolis: Vozes. 133p.

Virilio, P. 1993. Espaço Crítico - e as perspectivas do tempo real. Tradução de Paulo Roberto Pires. São Paulo: Editora 34. 144p.

Williams, R. 1990. O Campo e a Cidade. Tradução de. São Paulo: Companhia da Letras. 439p.

Yúdice, G. 2006. A conveniência da cultura: usos da cultura na era global. Tradução de Marie-Annee Silva. Belo Horizonte: Editora UFMG. 651p. 